\title{
Differential Effect of Population Density on Shape and Size of Cylindrical Red Beet (Beta vulgaris L. ) Genotypes
}

\author{
I.L. Goldman \\ Department of Horticulture, University of Wisconsin-Madison, 1575 Linden Drive, Madison, WI 53706
}

Additional index words. root shape

\begin{abstract}
The effects of population density on shape and size of cylindrical red beet genotypes were evaluated in a field experiment during 1994 and 1995. Two $F_{1}$ hybrids and two open-pollinated genotypes were planted in replicated trials consisting of three population densities. Y ield, harvest weight, percent harvestable beets per plot, length, middle width, top width, bottom width, length $\mathrm{x}$ width, length to width ratio, and a shape index (SI) were measured on a sample of beet plants from each plot. The density $x$ genotype interaction was nonsignificant for all 10 traits. Averaged over genotypes, significant differences among densities were found for harvest weight, percent harvestable beets per plot, length, middle width, and length $x$ width. In general, greater harvest weights, a higher percentage of harvestable beets, and greater length, middle width, and length $\mathbf{x}$ width values were found at low density. Averaged over densities, significant differences among genotypes were measured for all 10 traits. The open-pollinated genotypes Cyndor and Cylindra exhibited lower yield, lower harvest weight, greater SI, and a higher percentage of harvestable beets than their hybrid counterparts. These data demonstrate that population density has a differential and significant effect on the shape and size of cylindrical beet genotypes.
\end{abstract}

The size and shape of traditional globe-shaped red beet roots are determined in part by population density and within-row spacing. Using cylindrically shaped red beet genotypes to produce processing beets has increased recently; however, retention of their cylindrical or tube shape (cylindrical uniformity) may be affected by population density and row spacing. Currently, little is known about cultural practices affecting the size and shape of cylindrical red beets. Although cylindrical or long red beet germplasm sources have been available for many years (Magruder et al., 1940), few workers have conducted studies comparing their production efficiency to that of traditional globe-shaped genotypes. Perhaps the primary impetus behind using cylindrical varieties is that, in slicing and canning operations, their roots yield a larger percentage of usable uniform slices than traditional globe-shaped roots. Although there may be less waste during canning operations, fluctuation in the cylindrical shape and size of these roots grown under different production systems may mitigate this advantage. Shape and size of globe-shaped red beet genotypes is determined largely by population density and within-row spacing (Benjamin and Sutherland, 1985; Mack, 1979). Currently, little work to determine the relationship between population density and size and shape of cylindrical genotypes has been conducted. In addition to deviations in tubular shape, cylindrical roots may display a crook-neck appearance, which affects the quantity of desirable slices per root. This characteristic is caused by a bending of the hypocotyl portion of the root and may or may not be affected by population density. Despite this factor, information regarding the relationship between

Received for publication 13 Feb. 1995. Accepted for publication 7 June 1995. This research supported by Hatch project 3654, Wisconsin Agricultural Experiment Station, College of Agricultural and Life Sciences, Univ. of Wisconsin-Madison. I am indebted to Bob Hughes, Bruce Michaelis, and Larry Binning for their assistance with fieldoperations and technical advice; Jon Behling, Alf Christianson Seed Co., for germplasm; and Nick Breitbach, Mary Palmer, Karen Eagen, and Min Wang for technical assistance. The cost of publishing this paper was defrayed in part by the payment of page charges. Under postal regulations, this paper therefore must be hereby marked advertisement solely to indicate this fact.

${ }^{1}$ Assistant professor. population density and the degree of cylindrical root shape is necessary to produce cylindrical red beet roots.

A strong relationship between population density and yield of globe-shaped red beet has been observed (Benjamin, 1987; Benjamin and Bell, 1985; Benjamin and Sutherland, 1985). Results from these experiments suggest that the highest yield of desirable small size grades ( 25 to $50 \mathrm{~mm}$ in diameter) of globe-shaped beets for processing is obtained with high population densities. Furthermore, within-row spacing is far more critical to producing small size grades of beets than between-row spacing (Benjamin and Sutherland, 1985). These workers determined that the highest yields of small size grades of globe-shaped beets were obtained at densities up to $200 \mathrm{~m}^{2}$. Mack (1979) demonstrated that higher yields of smaller size grades of globe-shaped red beets were produced in narrow-row compared to wide-row production systems. Yield of small size grades of beets $(<25 \mathrm{~mm}$ in diameter) increased more than 2-fold with reduced row spacing from $30 \mathrm{~cm}$ to $15 \mathrm{~cm}$ (Mack, 1979). Although red beet processors may use beets from 25 to $100 \mathrm{~mm}$ in diameter, producing smaller size grades is possible by varying production methods. Mack (1979) and Benjamin and Bell (1985) demonstrated that the diameter of globe-shaped beets increases with decreasing population density, thus reducing economic yield. If the diameter of cylindrical beets increases with decreasing population density and a more globeshaped root results, some of the suspected advantages of cylindrical genotypes may be negated.

Present production practices for cylindrical beets are based on practices developed for globe-shaped varieties. In addition, these practices are conducted with limited information on optimal shape and density relationships. The objective of this investigation was to evaluate the effects of population density on shape and size of selected cylindrical red beet genotypes.

\section{Materials and Methods}

Field experiments were conducted at the Univ. of Wisconsin Horticulture Research Farm in Arlington, Wis., in 1993 and 1994. Four genotypes-two open-pollinated $(\mathrm{OP})$ and two hybrid $\left(\mathrm{F}_{1}\right)$ 
were used. Seed of Cylindra (OP), Cyndor (OP), CXA9026 ( $\left.\mathrm{F}_{1}\right)$, and CXA9027 $\left(\mathrm{F}_{1}\right)$ was obtained from Jon Behling of the Alf Christianson Seed Co. (Mt. Vernon, Wash.). Seed was machineplanted with a Nibex planter in four-row plots at three population densities. The three densities-25, 50, and 82 seeds/m-corresponded to about 88,000 (low), 175,000 (medium), and 294,000 (high) plants/ha, respectively. Plots were $3.7 \mathrm{~m}$ long with a between-row spacing of $46 \mathrm{~cm}$. Planting dates were 7 June and 5 May in 1993 and 1994, respectively. Plots were thinned to appropriate density 5 weeks after planting and harvested on $18 \mathrm{Aug}$. and 28 July in 1993 and 1994, respectively.

The experiment was planted in three replications using a randomized complete-block design. A 2.4-m section from the two center rows of each four-row plot was harvested and weighed. Beets were then passed through a $5-\mathrm{cm}$ screen and both resulting fractions were weighed. A randomly chosen sample of 20 beets from each plot was used for shape analysis. Beets were sliced longitudinally and length was measured. Diameter at $1 \mathrm{~cm}$ from the base, crown, and midpoint between the base and the crown were also measured. A shape index (SI) was calculated as the difference among these three measurements; thus, roots with more of a cylindrical shape would exhibit less variation among these three measurements than round roots. Data were averaged over all 20 plants from each plot to obtain means for the analysis of variance. The following traits were considered: total plot yield, harvest weight per plot as the weight of beets that pass through a $5-\mathrm{cm}$ screen, percent harvestable beets as the percentage of roots (by weight) in each plot smaller than $5 \mathrm{~cm}$, length $\times$ width as the product of the mean beet width and the beet length, length to width ration as the beet length divided by the mean beet width, straightness as measured by the difference between the center width and the average of the top and bottom beet widths, and length, middle width, top width, and bottom width. Data were subjected to analysis of variance using the GLM procedure of SAS (SAS Institute, Cary, N.C.). Genotypes and densities were considered as fixed effects in the analysis of variance.

\section{Results and Discussion}

The analysis of variance revealed no significant year $\times$ genotype, year $\times$ density, or year $\times$ density $\times$ genotype interactions; thus, these interaction terms were pooled in subsequent analyses (Table 1). The effect of density was significant for percent harvestablebeets at $P<0.01$ and for length $\times$ width, harvest weight, length, and middle width at $P<0.10$. The main effect of genotype was significant for all 10 traits measured. The density $\times$ genotype interaction was significant only for bottom width.

The percentage of harvestable beets was significantly higher in the low density planting, followed by the medium density and the high density planting (Table 2). This finding demonstrates that there were more beets $>5 \mathrm{~cm}$ in diameter at lower population densities at this harvest stage. It is expected that medium- and highdensity plantings will yield beets of favored processing size at later harvest dates. Harvest weight also decreased with increasing density, revealing an increase of $>15 \%$ at low density compared to medium density. No significant difference was measured between medium and high density for harvest weight. Length, middle width, and length $\times$ width decreased with increasing density. Length $\mathbf{x}$ width values were $22 \%$ lower at high than low densities. Length decreased significantly from low to medium densities but not from medium to high densities. These data suggest that beets with greater length and width result from lower-density plantings. This finding agrees with the results obtained by Benjamin and Bell (1985) for globe-shaped beets. Although more cylindrical roots (as measured by the SI) were observed at high densities, no significant difference between the SI at the three densities was observed. A nonsignificant trend demonstrating differences in the SI were greater at the low and middle densities than at the high density. Similar trends were observed for length $\times$ width. Averaged over genotype, cylindrical beets exhibited greater harvest weight, percent harvestability, length $\times$ width, length, and middle width at lower densities compared to medium and high densities.

Highly significant differences among genotypes were observed

Table 1. Mean squares from the analysis of variance of four cylindrical red beet cultivars grown at three densities for 2 years.

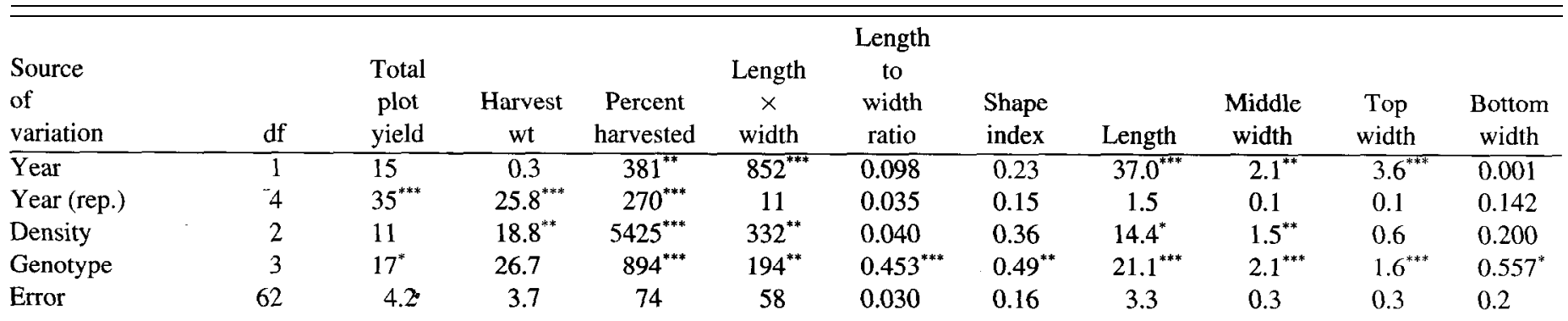

***,***Significant at $P<0.10,0.05$, or 0.01 , respectively.

Table 2. Effect of density on selected yield and shape parameters of four cylindrical beet cultivars grown at Arlington, Wis., averaged over years.

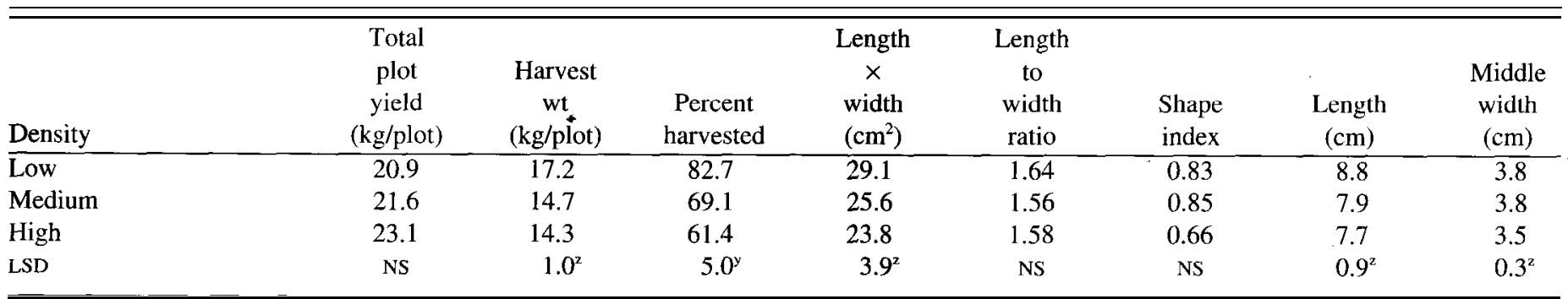

${ }_{\overline{\mathrm{M}}} \overline{\mathrm{Mean}}$ differences exceeding this value are significantly different at $P<0.10$.

'Mean differences exceeding this value are significantly different at $P<0.05$. 
Table 3. Yield and shape parameters of four cylindrical beet cultivars grown at Arlington, Wis., averaged over three densities and 2 years.

\begin{tabular}{|c|c|c|c|c|c|c|c|c|c|c|}
\hline Density & $\begin{array}{c}\text { Total } \\
\text { plot } \\
\text { yield } \\
\text { (kg/plot) }\end{array}$ & $\begin{array}{c}\text { Harvest } \\
\text { wt } \\
\text { (kg/plot) }\end{array}$ & $\begin{array}{c}\text { Percent } \\
\text { harvested }\end{array}$ & $\begin{array}{c}\text { Length } \\
\times \\
\text { width } \\
\left(\mathrm{c} \mathrm{m}^{2}\right)\end{array}$ & $\begin{array}{l}\text { Length } \\
\text { to } \\
\text { width } \\
\text { ratio }\end{array}$ & $\begin{array}{c}\text { Shape } \\
\text { index }\end{array}$ & $\begin{array}{l}\text { Length } \\
(\mathrm{cm})\end{array}$ & $\begin{array}{c}\text { Middle } \\
\text { width } \\
(\mathrm{cm})\end{array}$ & $\begin{array}{r}\text { Top } \\
\text { width } \\
(\mathrm{cm})\end{array}$ & $\begin{array}{l}\text { Bottom } \\
\text { width } \\
(\mathrm{cm})\end{array}$ \\
\hline Cyndor & 18.7 & 12.5 & 67.1 & 26.0 & 1.50 & 0.73 & 7.7 & 3.9 & 3.5 & 2.7 \\
\hline Cylindra & 22.2 & 13.9 & 63.1 & 26.4 & 1.81 & 0.57 & 9.2 & 3.2 & 3.0 & 2.3 \\
\hline CXA 9026 & 22.9 & 17.2 & 76.7 & 30.1 & 1.61 & 0.90 & 8.8 & 3.9 & 3.6 & 2.5 \\
\hline CXA 9027 & 23.5 & 18.3 & 77.3 & 22.0 & 1.46 & 0.93 & 6.8 & 3.8 & 3.4 & 2.4 \\
\hline LSD $0.05^{2}$ & 3.1 & 2.9 & 5.8 & 5.4 & 0.12 & 0.28 & 1.3 & 0.4 & 0.4 & 0.3 \\
\hline
\end{tabular}

${ }^{\mathrm{z}}$ Mean differences exceeding this value are significant at $P<0.05$.

for six of ten traits, and significant differences among genotypes were observed for the remaining four traits. Averaged over densities, Cylindra, CXA9026, and CXA9027 yielded more than Cyndor (Table 3). The open-pollinated genotypes Cyndor and Cylindra averaged lower yields than the hybrids CXA9026 and CXA9027. Harvest weight was also significantly lower in the open-pollinated genotypes. Averaged over densities, the open-pollinated genotypes exhibited $33 \%$ lower harvest weights than their hybrid counterparts. Percent harvestability was lower in open-pollinated genotypes $(65.4 \%)$ compared to hybrids $(77 \%)$. This finding may indicate greater growth rates in hybrid genotypes, a phenomenon well documented in many hybrid crop plants. From a practical standpoint, these results demonstrate that, by this harvest date, significantly more beets from hybrid than open-pollinated genotypes had reached a desirable processing size.

In general, Cyndor and Cylindra were lower in yield, harvest weight, percent harvestability, length $\times$ width, length to width ratio, and SI than CXA9026 and CXA9027. Cyndor exhibited significantly greater middle width, top width, and bottom width than Cylindra; however, Cylindra had significantly greater length. In general, Cyndor exhibited middle width, top width, and bottom width equal to the hybrid genotypes. Cylindra was significantly longer than the other three genotypes but exhibited lower values for other shape parameters. Both hybrid genotypes exhibited high values for productivity and shape traits. CXA9026 ranked highly for all productivity and shape traits, while CXA9027 ranked highly for all productivity traits.

Cylindrical roots may display acrook-neck appearance, wherein an obtuse angle between the taproot and the hypocotyl forms as roots emerge from soil. The crook-neck shape decreases the yield of beet slices because of processing difficulties during canning operations. While this tendency remains an important factor in producing cylindrical varieties, it is unclear whether population density and within-row spacing affects this characteristic. Further research is needed to assess this aspect of root shape in cylindrical genotypes.

In summary, these data demonstrate variability for response to population density among cylindrical red beet genotypes. The effects of population density were primarily noted on percent harvestable beets but not on yield and harvest weight. Trends toward reduced length and width with increasing density were also noted, suggesting that certain aspects of beet shape may be manipulated by controlling population density. Hybrid genotypes were generally more productive than open-pollinated genotypes; however, the differences in top, middle, and bottom width of a longitudinal root slice were greater in hybrid than in open-pollinated genotypes. Straightness of cylindrical beets, as determined by the relationship among these three measurements and reflecting the tubular nature of the root, therefore depends on genotype and population density. Additional investigation is needed to determine optimal population densities of cylindrical genotypes for maximum production of small size grade beets.

\section{Literature Cited}

Benjamin, L.R. and R.A. Sutherland. 1985. The influence of sowing rate and row spacing on the plant density and yield of red beet. J. Agr. Sci. Camb. 104:615-624.

Benjamin, L.R. and N. Bell. 1985. The influence of seed type and plant density on variation in plant size of red beet (Beta vulgaris L.) crops. J. Agr. Sci. Camb. 105:563-571.

Benjamin, L.R. 1987. The relative importance of cluster size, sowing depth, time of seedling emergence and between-plant spacing on variation in plant size in red beet (Beta vulgaris L. ) crops. J. Agr. Sci. Camb. 108:221-230.

Mack, H.J. 1979. Effects of row spacings, fertilizers, and harvest dates on table beets. J . Amer. Soc. Hort Sci. 104:717-720.

Magruder, R., V.R. Boswell, H.A.. Jones, J.C. Miller, J.F. Wood, L.R. Hawthorn, M.M. Parker, and H.H. Zimmerley. 1940. Descriptions of types of principal American varieties of red garden beets. U.S. Dept. of Agr. Misc. Publ. 374. 